\title{
The role of emotional states in fruit and vegetable consumption in Brazilian adults
}

\author{
O papel dos estados emocionais \\ no consumo de frutas e vegetais em adultos brasileiros
}

Helena Beatriz Rower ${ }^{1}$

Maria Teresa Anselmo Olinto ${ }^{1}$

Tonantzin Ribeiro Gonçalves ${ }^{1}$

Marcos Pascoal Pattussi ${ }^{1}$

${ }^{1}$ Programa de Pós-

Graduação em Saúde

Coletiva, Universidade do

Vale do Rio dos Sinos. Av.

Unisinos 950, Cristo Rei.

93022-000 São Leopoldo

RS Brasil.

mppattussi@unisinos.br

\begin{abstract}
The objective was to investigate the association between emotional states with adequate fruit and vegetable consumption (FVC). This is a population-based cross-sectional study with 1,100 adults from a medium-sized city in Southern Brazil. Adequate FVC was defined as concomitant intake $\geq 3$ fruits and $\geq 5$ tablespoons of vegetables per day. Exposures were self-perception of nervousness/stress and minor psychiatric disorders (MPD). Data analysis used logistic regression. After controlling for demographic, socioeconomic and behavioral variables, adults reporting lack of nervousness/stress were twice more likely to report adequate FVC than those who reported it. Similarly, those reporting not having MPD symptoms were $52 \%$ more likely to have adequate FVC than those who did not. These effects increased and remained significant among women.
\end{abstract}

Key words Self concept, Mental health, Minor psychiatric disorders, Fruit and vegetable intake
Resumo O objetivo foi verificar a associação entre a autopercepção do estado emocional com o consumo adequado de frutas, verduras e legumes (FVL). Este é um estudo transversal de base populacional com uma amostra probabilística de 1100 adultos residentes na zona urbana de um município de médio porte do Brasil. Considerou-se como consumo adequado uma ingestão $\geq 3$ frutas concomitante com $\geq 5$ colheres de verduras/legumes ao dia. O estado emocional foi avaliado através da autopercepção do nervosismo/stress e distúrbios psiquiátricos menores (DPM). Potenciais fatores de confundimento incluíam variáveis demográficas, socioeconômicas e comportamentais. Foram observadas associações significativas entre a autopercepção de nervosismo/stress e DPM com o consumo adequado de FVL. Após o controle de fatores de confusão, adultos relatando ausência de nervosismo/stress possuíam uma chance de apresentar um consumo adequado duas vezes maior do que aqueles relatando nervosismo/stress. Similarmente, participantes com ausência de distúrbios psiquiátricos possuíam uma chance de consumo adequado FVL 52\% mais elevada quando comparados àqueles que relataram presença desses sintomas. Quando estratificada por gênero, esse efeito aumentou e manteve-se com significância estatística apenas entre as mulheres.

Palavras-chave Autopercepção de nervosismo/ stress, DPM, Consumo de frutas, verduras e legumes 


\section{Introduction}

The rapid changes in population dietary patterns along with reductions in malnutrition and increases in obesity rates elicit global concern ${ }^{1,2}$. In Brazil, large national surveys such as the National Survey of Household Expenditure in 1974-1975, the National Survey on Health and Nutrition in 1989 and the Consumer Expenditure Surveys in 2002-2003 and 2008-2009 have shown that, in all regions of the country and in all age and income categories, the percentages of overweight and obese people have increased continuously and substantially ${ }^{1,3}$. There has been a concomitant increase in the consumption of processed products, which are rich in refined carbohydrates and fats, and a decrease in the consumption of fruits and vegetables $(\mathrm{FV})^{1,2}$.

There is considerable evidence for the protective roles of an adequate consumption of $\mathrm{FV}$ in the prevention of obesity and of chronic non-communicable diseases (NCDs) such as diabetes $^{4}$ and, cardiovascular diseases ${ }^{5}$. It has also been shown that regular consumption of FV facilitate the prevention of asthma, iron deficiency anaemia ${ }^{6}$ and mental disorders ${ }^{7,8}$.

Previous studies also indicate that FV intake is strongly influenced by demographic and economic aspects. Generally, women, married and white people, those with better education and income, physically active, non-smokers, and with moderate alcohol consumption habits tend to consume adequately $\mathrm{FV}^{9-12}$.

There has also been increasing interest on the role of emotional states on eating behaviour. Aspects such as anger, sadness, daily stressors and other stressful situations may affect the whole process of intake (e.g., motivation to eat, food choices, chewing, time spent eating, amount of food intake), as well as metabolism and digestion $^{13}$. Several studies have reported the association between adequate consumption of FV and favourable mental states ${ }^{7,8,14-17}$. Absence of association has also been reported ${ }^{18}$. The aim of this study was to investigate the association between emotional states and FV intake in adults from a medium-sized city in southern Brazil.

\section{Materials and methods}

\section{Design and procedure}

This is a population-based cross-sectional study of a representative sample of adults aged
18 years or more who live in the city. In 2010, the municipal area included 214,087 inhabitants, of whom $109,845(51.3 \%)$ were females and $104,242(49.7 \%)$ were males ${ }^{19}$.

The data were collected in 2006 and 2007 through structured interviews with a standardized and pre-tested questionnaire that comprised demographic, socioeconomic, behavioural, and mental health variables. A pilot study of the instrument with 100 people and a quality control with approximately $10 \%$ of the sample was performed.

\section{Sampling}

The sample size calculation was based on data from the pilot study, using the method for proportions with conglomerate randomization ${ }^{20}$ and taking the self-perception health outcome. The sample size was calculated to have $85 \%$ power $(1-=0.85)$ to detect a difference of $7 \%$ in the prevalence of poor self-perceived health, with $95 \%$ confidence. A number of 35 households per sector and an intra-class correlation coefficient of 0.05 were adopted. From this, a sample of 1,260 households in 36 sectors was estimated. The sample size was increased by $20 \%$ in the number of households and $10 \%$ in the number of sectors, due to possible losses and the control of confounding factors in the data analysis. Thus, it was necessary to access a total of 1,512 households in 40 census tracts.

Participant selection occurred in 2 stages. First, a random selection of census tracts was conducted among the 270 existing tracts in the urban city area. Next, blocks were randomly selected within the sectors, and all households were visited. If, after completing the block, a sufficient number of households had not been visited, the interviewer would complete another block of the previously drawn sector. Questionnaires were administered at home to the person responsible for the household at the time of the interview. Persons under the age of 18 were excluded.

\section{Outcome}

Adequate FV consumption was assessed by 2 questions as follows: 1) the amount of fruit or natural fruit juice consumed per day, and 2) the number of tablespoons of vegetables consumed per day. In Brazil, the recommendation for adequate $\mathrm{FV}$ intake is 3 portions of fruits and 3 portions of vegetables, for a total of 6 daily portions of fruits and vegetables ${ }^{21}$. If this criterion 
was used in this study, only 40 participants could participate in the analysis, which would significantly decrease the statistical power with which to detect associations. Therefore, it was decided to conduct the analysis according to the criteria used in studies from countries where the recommendations suggested the consumption of $5 \mathrm{FV}$ portions ${ }^{22,23}$. Therefore, adequate consumption was defined as the concomitant intake of 3 or more fruits (or natural fruit juices) and 5 or more tablespoons of vegetables per day.

\section{Exposures}

The exposures were assessed as the self-perceptions of nervousness/stress and the presence of minor psychiatric disorders (MPD). The former was assessed by the perceptions of nervousness/stress using the following question: "Do you see yourself as a nervous person?" The possible answers were "no", "sometimes" and "yes". The latter, used the Self-Report Questionnaire (SRQ20), which consists of 20 questions and permits the tracking of MPDs (e.g., depression, anxiety, somatoform disorders and neurasthenia). The SRQ-20 has shown high sensitivity (83\%) and specificity (80\%) for the Brazilian population ${ }^{24}$. Despite the fact that its results do not mean a clinical diagnosis, the World Health Organization recommends the SRQ-20 for this purpose and this tool has been shown to be effective in MPD detection $^{25}$. The cut-off points were six positive responses for males and seven for females.

\section{Confounding factors}

The confounding factors included demographic, socioeconomic and behavioural variables. The demographic variables were age (10-yearrange age groups), race (white, black and other) and marital status (married, single or divorced/ alone). The socioeconomic variables were family income (in R\$) and education (years of schooling), which were further categorized into high (highest 25\% of the individual scores), medium (intermediate $50 \%$ of the scores) and low (lowest $25 \%$ of the scores). The behavioural variables included smoking (non-smoker or smoker), physical activity (insufficiently active: do not practice physical activity or practice for up to 150 minutes/ week or active:> 150 minutes/week $)^{26}$ and alcohol consumption (do not consume/consume moderately: < 24AU/month for women and $<40 \mathrm{AU} /$ month for men or yes/excess: $>24 \mathrm{AU} /$ month for women and $>40 \mathrm{AU} /$ month for men $)^{27}$.

\section{Data analysis}

Double data entry was performed with the Epi Info 6 program, version 6.0 (Center for Disease Control and Prevention, Atlanta, GA, USA) to identify typos. Data analysis was performed with the Stata 11.0 program (Stata Corp., College Station, TX, USA) in 2012. A controlled logistic regression for complex samples was used to provide estimate of the crude and adjusted odds ratios (OR) and their respective 95\% confidence interval ranges (95\% CI). Only the potential confounding factors were entered in the multivariable analysis. The variable must have been associated with both the exposure and the outcome at a significance level $<20 \%(\mathrm{p}<0,20)$ to be considered a confounding factor. After conducting the analysis, the interactions between expositions and gender were tested. The gender variable was found to be a potential modifier of the exposure effect on the outcome $(\mathrm{P}=0.128$ and $\mathrm{P}=0.132)$. Therefore, analyses were conducted separately for males and females.

\section{Ethics}

The research project was approved by the Research Ethics Committee of Vale do Rio dos Sinos University, and all participants signed an informed consent.

\section{Results}

A total of 1,100 people were interviewed from 38 census tracts in the city. Eight per cent of the selected places were uninhabited or were trading points. Overall, $4 \%$ of the individuals refused to participate and those responsible for the households were not found in $2 \%$ of the cases, even after the interviewer returned on 3 separate occasions.

\section{Adequate FV consumption}

The overall prevalence of adequate FV consumption was $11.6 \%$ (95\% CI 9.7 to $13.5 \%$ ). Similar prevalence rates were found in males and females. Higher prevalence rates of adequate FV consumption were found in older, white, married and divorced/alone people with higher income and education levels, as well as non-smokers and those who were physically active (Table 1). 
Table 1. Prevalence of adequate fruit and vegetable consumption according to demographic, socioeconomic and behavioral variables.

\begin{tabular}{|c|c|c|c|c|c|c|}
\hline & \multicolumn{2}{|c|}{ Total } & \multicolumn{2}{|c|}{ Men } & \multicolumn{2}{|c|}{ Women } \\
\hline & \multicolumn{6}{|c|}{$\%$ of adequate consumption of FV } \\
\hline & $\mathbf{n}$ & $\%$ & $\mathbf{n}$ & $\%$ & $\mathbf{n}$ & $\%$ \\
\hline \multicolumn{7}{|c|}{ Fruit and Vegetable Consuption } \\
\hline Adequate & 128 & 11,6 & 36 & 11,6 & 92 & 11,6 \\
\hline Inadequate & 972 & & & & & \\
\hline \multicolumn{7}{|c|}{ Selfperception nervousness/stress } \\
\hline Yes & 310 & 7,7 & 49 & 12,2 & 261 & 6,9 \\
\hline Sometimes & 319 & 10,3 & 85 & 4,7 & 234 & 12,4 \\
\hline No & 470 & 15,1 & 175 & 14,9 & 295 & 15,3 \\
\hline \multicolumn{7}{|c|}{ Minor Psychiatric Disorders } \\
\hline Yes & 349 & 8,9 & 71 & 11,3 & 278 & 8,3 \\
\hline No & 748 & 13,0 & 239 & 11,7 & 509 & 13,6 \\
\hline \multicolumn{7}{|l|}{ Skin color } \\
\hline White & 922 & 12,1 & 260 & 11,2 & 662 & 12,5 \\
\hline Other & 101 & 8,9 & 25 & 12 & 76 & 7,9 \\
\hline Black & 58 & 6,9 & 17 & 5,9 & 41 & 7,3 \\
\hline \multicolumn{7}{|l|}{ Age group } \\
\hline $18-29$ & 247 & 8,1 & 69 & 5,8 & 178 & 9,0 \\
\hline $30-39$ & 182 & 9,3 & 46 & 8,7 & 136 & 9,6 \\
\hline $40-49$ & 258 & 10,5 & 66 & 7,6 & 192 & 11,5 \\
\hline $50-59$ & 217 & 16,6 & 62 & 21,0 & 155 & 14,8 \\
\hline$>=60$ & 196 & 14,3 & 67 & 14,9 & 129 & 14,0 \\
\hline \multicolumn{7}{|l|}{ Marital status } \\
\hline Married & 615 & 12,8 & 180 & 13,9 & 435 & 12,4 \\
\hline Single & 267 & 9,0 & 86 & 9,3 & 181 & 8,8 \\
\hline Divorced/Alone & 218 & 11,5 & 44 & 6,8 & 174 & 12,6 \\
\hline \multicolumn{7}{|l|}{ Income $^{\mathrm{a}}$} \\
\hline Low & 235 & 7,7 & 27 & 0,0 & 208 & 8,7 \\
\hline Medium & 565 & 11,2 & 154 & 10,4 & 411 & 11,4 \\
\hline High & 268 & 16,4 & 117 & 15,4 & 151 & 17,2 \\
\hline \multicolumn{7}{|l|}{ Schooling ${ }^{\mathrm{b}}$} \\
\hline Low & 204 & 9,3 & 39 & 5,1 & 165 & 10,3 \\
\hline Medium & 697 & 10,6 & 203 & 12,3 & 494 & 9,9 \\
\hline High & 166 & 16,9 & 51 & 9,8 & 115 & 20,0 \\
\hline
\end{tabular}

\section{Self-concept and mental disorders}

Adults who reported a lack of nervousness/ stress were approximately twice more likely to re- port adequate FV consumption than those who reported nervousness/stress Similarly, participants with no MPD indicators were 53\% more likely to report adequate FV consumption when 
Table 1. continuation

\begin{tabular}{|c|c|c|c|c|c|c|}
\hline & \multicolumn{2}{|c|}{ Total } & \multicolumn{2}{|c|}{ Men } & \multicolumn{2}{|c|}{ Women } \\
\hline & \multicolumn{6}{|c|}{$\%$ of adequate consumption of FV } \\
\hline & $\mathbf{n}$ & $\%$ & $\mathbf{n}$ & $\%$ & $\mathbf{n}$ & $\%$ \\
\hline \multicolumn{7}{|l|}{ Smoking } \\
\hline Smoker & 262 & 9,9 & 76 & 10,5 & 186 & 9,7 \\
\hline No smoker & 838 & 12,2 & 234 & 12 & 604 & 12,3 \\
\hline \multicolumn{7}{|c|}{ Excessive Alcohol Consumption ${ }^{c}$} \\
\hline Sim & 60 & 11,7 & 33 & 12,1 & 27 & 11,9 \\
\hline Não & 1037 & 11,7 & 275 & 11,6 & 762 & 11,9 \\
\hline \multicolumn{7}{|l|}{ Physical activity ${ }^{\mathrm{d}}$} \\
\hline Insufficiently active & 527 & 9,9 & 143 & 11,9 & 384 & 9,1 \\
\hline Active & 569 & 13,4 & 167 & 11,4 & 402 & 14,2 \\
\hline
\end{tabular}

${ }^{\text {a }}$ Income in Brazilian Reals (R\$): Low (lowest 25\% of the individual scores), Medium (intermediate $50 \%$ of the scores), High (highest $25 \%$ of the scores). ${ }^{\mathrm{b}}$ Educational level in years: Low (lowest $25 \%$ of the individual scores), Medium (intermediate $50 \%$ of the scores), High (highest $25 \%$ of the scores). ${ }^{c}$ Do not consume/consume moderately: $<24 \mathrm{AU} / \mathrm{month}$ for women and $<40$ $\mathrm{AU} / \mathrm{month}$ for men; yes/excess: $>24 \mathrm{AU} / \mathrm{month}$ for women and $>40 \mathrm{AU} / \mathrm{month}$ for men. ${ }^{\mathrm{d}}$ Insufficiently active: do not practice physical activity or practice for less than $150 \mathrm{~min} /$ week; active: $>150 \mathrm{~min} /$ week.

compared to those who reported the presence of MPD. After controlling for confounding factors, these expositions remained independently associated with the outcome and maintained their effect measures with the same clinical and statistical effects (Table 2).

The stratified analysis by gender showed that the effects of psychological variables increased and remained statistically significant only in women. After controlling for socioeconomic, demographic and behavioural variables, women who reported a lack of nervousness/stress were 2.32-fold more likely to report adequate FV consumption than those who reported nervousness/ stress. Likewise, women with no MPD were $68 \%$ more likely to report adequate FV consumption when compared to those who reported the presence of MPD indicators.

\section{Discussion}

The present study aimed to investigate the association between self-perceptions of nervousness/ stress and MPD with FV consumption. The main findings suggest that there is a significant association between favourable mental states and adequate FV consumption, particularly among women.
Several other studies in different countries found similar results. Five large cross-sectional studies that were conducted between 2000 and 2009 and included more than 250,000 Canadians found a strong inverse association between FV consumption and the presence of depression symptoms, mood swings and anxiety ${ }^{16}$. In the same light, a cohort study of 3,486 participants showed that people with dietary patterns based on FV and fish had lower rates of depression symptoms ${ }^{7}$. Another cohort study of 9,272 men and 3,132 women, aged between 45 and 60 years old, showed that a higher FV intake was associated with a lower likelihood of depressive symptoms ${ }^{14}$. Other large cross-sectional studies of elderly subjects in China ${ }^{17}$ and college students ${ }^{15}$ demonstrated that lower FV consumption was associated with the presence of stress and depressive symptoms. Finally, a cross-sectional study that included more than 18,000 people in the former Soviet Union reported that participants who reported fewer depressive symptoms also reported higher FV consumption ${ }^{28}$.

The results of this study suggest that, in the study population, the associations were limited to women. This suggests that men and women might react differently to stressful situations and emotional demands and those psychological symptoms tend to more directly influence 
Table 2. Unadjusted and adjusted odds ratios for adequate fruit and vegetable consumption associated with emotional states.

\begin{tabular}{|c|c|c|c|c|}
\hline & \multicolumn{2}{|c|}{ Unadjusted } & \multicolumn{2}{|c|}{ Adjusted } \\
\hline & OR (IC 95\%) & $\mathbf{p}$ & OR (IC 95\%) & p \\
\hline \multicolumn{5}{|c|}{ Selfperception nervousness/stress } \\
\hline Total sample & & 0,006 & & 0,010 \\
\hline Yes & 1 & & $1^{\mathrm{a}}$ & \\
\hline Sometimes & $1,38(0,84-2,25)$ & & $1,38(0,80-2,38)$ & \\
\hline No & $2,12(1,25-3,59)$ & & $1,99(1,17-3,37)$ & \\
\hline Men & & 0,210 & & 0,310 \\
\hline Yes & 1 & & $1^{\mathrm{b}}$ & \\
\hline Sometimes & $0,35(0,09-1,32)$ & & $0,31(0,08-1,26)$ & \\
\hline No & $1,25(0,48-3,23)$ & & $1,03(0,35-3,00)$ & \\
\hline Women & & 0,003 & & 0,006 \\
\hline Yes & 1 & & $1^{\mathrm{c}}$ & \\
\hline Sometimes & $1,91(1,03-3,59)$ & & $1,95(1,02-3,74)$ & \\
\hline No & $2,43(1,37-4,32)$ & & $2,32(1,25-4,28)$ & \\
\hline \multicolumn{5}{|c|}{ Minor Psychiatric Disorders } \\
\hline Total sample & & 0,018 & & 0,016 \\
\hline with MPD & 1 & & $1^{\mathrm{d}}$ & \\
\hline without MPD & $1,53(1,08-2,16)$ & & $1,52(1,10-2,10)$ & \\
\hline Men & & 0,918 & & 0,882 \\
\hline with MPD & 1 & & $1^{\mathrm{b}}$ & \\
\hline without MPD & $1,05(0,45-2,40)$ & & $1,07(0,41-2,82)$ & \\
\hline Women & & 0,029 & & 0,074 \\
\hline with MPD & 1 & & $1^{\mathrm{e}}$ & \\
\hline without MPD & $1,74(1,06-2,86)$ & & $1,68(0,96-2,94)$ & \\
\hline
\end{tabular}

${ }^{a}$ Adjusted OR for income, education and physical activity. ${ }^{b}$ Adjusted OR for income and education. ${ }^{c}$ Adjusted OR for income, education and physical activity. ${ }^{\mathrm{d}}$ Adjusted OR for age, income, education and physical activity. ${ }^{\mathrm{e}}$ Adjusted OR for age, marital status, income, education and physical activity.

women's eating habits. It has been suggested that women might be more likely to eat in response to stressful situations ${ }^{14,29,30}$, at which times they would increase the total amount of consumed food $^{31}$ or, in particular, the consumption of carbohydrates and fats ${ }^{32}$. However, women tend to consume more fruits when they are not under stress $^{32,33}$. In contrast, men tend to eat unhealthy foods regardless of the emotional situation ${ }^{32}$, and the greatest reported influence on men is related to socioeconomic aspects ${ }^{31}$. Simultaneously, in stressful situations, there is evidence that men are more likely to use alcoholic beverages, cigarettes and other drugs ${ }^{34}$.

The action mechanisms behind the association between mental states and adequate FV consumption are complex and thus require further studies ${ }^{15,35,36}$. On one hand, individually stressful situations are presented as those that cause increased excretion of corticosteroids and adrenergic hormones, which are associated with a high consumption of foods with saturated fat, and decreased FV intake. Accordingly, it has been suggested that the intake of foods rich in fats and sugars, which are considered palatable, satiogenic or comfort foods (affective foods), decrease the activity of neuronal circuits involved in stress mechanisms and thus act as protectors against the harmful effects of stress ${ }^{15,35,36}$. Repetitive hormonal and alimentary stimuli can act as external opioids that generate feelings of satisfaction and consequent overeating ${ }^{37-39}$. Additionally, an increase in leptin production (which is responsible for the sense of satiety), a mechanism of hormonal regulation, might be associated with the decreased consumption of comfort food ${ }^{40}$. 
Dietary changes are also considered to result from emotional eating. In this case, the eating behaviour is motivated by emotional and/or stressful situations and now operates in a feedback system related to emotions and food ${ }^{13}$. This process of regulation between food and emotions is also influenced by the individual's coping strategies with regard to the stressful situations ${ }^{41}$, as well as endocrine factors ${ }^{15,35,36}$, the context of the individual's life and/or aspects of his/her personality ${ }^{42}$. In regard to negative mental states such as depressive symptoms, for example, the literature has shown that there is an overall deterioration in the quality of consumed food, which may lead, in some cases, to a lack of appetite $e^{7,8,16}$.

A two-way relationship between food and mental states may exist, in which emotions affect both the quantity and quality of consumed food, and, in turn, the consumed food may affect the emotional wellbeing of the individual ${ }^{43}$. In addition, it could be considered that self-perceptions of nervousness, might be associated with methods of coping with milder and more transient stressful emotional states, while the MPD indicators may provide clues about the chronicity of negative emotional states. Therefore, further studies could investigate how the different coping strategies of individuals mediate the association between adequate FV consumption and mental health indicators.

One of the main weaknesses of this study refers to its cross-sectional nature. Because exposure and outcome were measured at the same time point, reverse causality may be present. Thus, it could be reasoned that, because emotions can affect the quality and quantity of consumed food, consumption could also affect emotional wellbeing $^{7,14,43}$. Thus, longitudinal studies are needed to elucidate the causal relationships. Furthermore, new studies could address gender differences with respect to this association in greater depth. On the other hand, this is a relatively unexplored field in the Brazilian context, the study was based on a representative sample of adults, the procedures adhered to high standards of methodological rigor and the analyses controlled for important confounding factors such as demographic, socioeconomic and behavioural variables.

Our findings could inform public policies targeting the promotion of healthy habits and therefore, fostering the protective role of FVL intake in preventing diseases. In addition, health professionals should take into account emotional states in designing and implementing programs targeting healthy eating. To sum up, although our results suggest that mental health may play an important role in adequate FV consumption, especially among women, other aspects such as reducing production and consumer costs of FVL for the whole population are essential to shape eating habits of the whole population ${ }^{44}$.

\section{Collaborations}

HB Rower originated the study, participated in data collection, reviewed the literature and wrote the manuscript. TR Gonçalves and MTA Olinto critically reviewed the article. MP Pattussi designed and supervised the study and data analysis. All authors interpreted results and approved the final version of the article.

\section{Acknowledgements}

The study was funded by Conselho Nacional de Desenvolvimento Científico e Tecnológico CNPq and by Fundação de Amparo a Pesquisa do Rio Grande do Sul - FAPERGS. MTA Olinto received a research productivity grant from. The funders had no role in study design, data collection and analysis, decision to publish and the preparation or approval of the manuscript. 
1. Schmidt MI, Duncan BB, Azevedo-e-Silva G, Menezes AM, Monteiro CA, Barreto SM, Chor D, Menezes PR. Chronic non-communicable diseases in Brazil: burden and current challenge. Lancet 2011; 377(9781):19491961.

2. Popkin BM, Adair LS, Ng SW. Global nutrition transition and the pandemic of obesity in developing countries. Nutrition Reviews 2012; 70(1):3-21.

3. Instituto Brasileiro de Geografia e Estatística (IBGE). Pesquisa de Orçamentos Familiares 2008-2009. Rio de Janeiro: IBGE; 2010.

4. Schulze MB, Liu S, Rimm EB, Manson JE, Willett WC, Hu FB. Glycemic index, glycemic load, and dietary fiber intake and incidence of type 2 diabetes in younger and middle-aged women. Am J Clin Nutr 2004; 80(2):34856.

5. Hooper L, Summerbell CD, Higgins JP, Thompson RL, Capps NE, Smith GD, et al. Dietary fat intake and prevention of cardiovascular disease: systematic review. $\mathrm{Br}$ Med J 2001; 322(7289):757-763.

6. Ruel G, Shi Z, Zuo H, Kroger E, Siriois C, Lévesque JF, Taylor AW. Association between nutrition and the evolution of multimorbidity: the importance of fruits and vegetables and whole grains products. Clin Nutr 2014; 33(3):513-520.

7. Akbaraly TN, Brunner EJ, Ferrie JE, Marmot MG, Kivimaki M, Singh-Manoux A. Dietary pattern and depressive symptoms in middle age. Br J Psychiatry 2009; 195(5):408-413.

8. Jacka FN, Mykletun A, Berk M, Bjelland I, Tell GS. The association between habitual diet quality and the common mental disorders in community-dwelling adults: the Hordaland Health study. Psychosom Med 2011; 73(6):483-490.

9. Azagba S, Sharaf MF. Disparities in the frequency of fruit and vegetable consumption by socio-demographic and lifestyle characteristics in Canada. Nutr J 2011; 10:118.

10. Dubowitz T, Heron M, Bird CE, Lurie N, Finch BK, Basurto-Dávila R, Hale L, Escarce JJ. Neighborhood socioeconomic status and fruit and vegetable intake among whites, blacks, and Mexican Americans in the United States. Am J Clin Nutr 2008; 87(6):1883-1891.

11. Myint P, Welch A, Bingham S, Surtees P, Wainwright N, Luben R, Wareham NJ, Smith RD, Harvey IM, Day NE, Khaw KT. Fruit and vegetable consumption and self-reported functional health in men and women in the European Prospective Investigation into Cancer-Norfolk (EPIC-Norfolk): a population-based cross-sectional study. Public Health Nutr 2007; 10(1):34-41.

12. Sieri S, Krogh V, Saieva C, Grobbee DE, Bergmann M, Rohrmann S, Tjønneland A, Ferrari P, Chloptsios Y, Dilis V, Jenab $\mathrm{M}$, Linseisen J, Wallström $\mathrm{P}$, Johansson I, Chirlaque MD, Sanchez MJ, Niravong M, ClavelChapelon F, Welch AA, Allen NE, Bueno-de-Mesquita HB, van der Schouw YT, Sacerdote C, Panico S, Parr CL, Braaten T, Olsen A, Jensen MK, Bingham S, Riboli E, Slimani N. Alcohol consumption patterns, diet and body weight in 10 European countries. Eur J Clin Nutr 2009; 63(Supl. 4):S81-100

13. Macht M. How emotions affect eating: a five-way model. Appetite 2008; 50(1):1-11.
14. Le Port A, Gueguen A, Kesse-Guyot E, Melchior M, Lemogne C, Nabi H, Goldberg M, Zins M, Czernichow S. Association between Dietary Patterns and Depressive Symptoms Over Time: A 10-Year Follow-Up Study of the GAZEL Cohort. PLoS One 2012; 7(12):e51593.

15. Liu C, Xie B, Chou CP, Koprowski C, Zhou D, Palmer P, Sun P, Guo Q, Duan L, Sun X, Anderson Johnson C. Perceived stress, depression and food consumption frequency in the college students of China Seven Cities. Physiol Behav 2007; 92(4):748-754.

16. McMartin SE, Jacka FN, Colman I. The association between fruit and vegetable consumption and mental health disorders: Evidence from five waves of a national survey of Canadians. Prevent Med 2013; 56(3-4):225230.

17. Woo J, Lynn H, Lau WY, Leung Jea. Nutrient intake and psychological health in an elderly Chinese population. Int J Geriatr Psychiatry 2006; 21(11):1036-1043.

18. Fulkerson JA, Sherwood NE, Perry CL, Neumark-Sztainer Dea. Depressive sumptoms and adolescent eating and health behaviors: a multifaceted view in a population-based sample. Prev Med 2004; 38(6):865-875.

19. Instituto Brasileiro de Geografia e Estatística (IBGE). IBGE Cidades. 2010. [cited 2013 Feb 25]. Available from: http://www.ibge.gov.br/cidadesat/painel/painel. php? $\operatorname{codmun}=431870$.

20. Hsieh FY. Sample size formulae for intervention studies with the cluster as unit of randomization. Stat Med 1988; 7(11):1195-1201.

21. Brasil. Ministério da Saúde (MS). Guia Alimentar para a População Brasileira. Brasília: MS; 2005.

22. USDA Services, editor. Dietary Guidelines for Americans. Government Printing Office: Washington; 2010.

23. The British Dietetic Association. Fruit and vegetables - how to get five-a-day. 2011. [cited 2013 Sep 4]. Available from: http://www.bda.uk.com/foodfacts/.

24. Mari JJ, Williams P. A validity study of a psychiatric screening questionnaire (SRQ-20) in primary care in the city of Sao Paulo. Br J Psychiatry 1986; 148:23-26.

25. Mari JJ, Iacopini E, Williams P, Simões O, Silva JBT. Detection of Psychiatric Morbidity in the Primary Medical Care Settings in Brazil. Rev Saude Publica 1987; 21(6):501-507.

26. Hallal PC, Victora CG. Reliability and validity of the International Physical Activity Questionnaire (IPAQ). Med Sci Sports Exerc 2004; 36(3):556.

27. Silveira CM, Silveira CC, Silva JG, Silveira LM, Andrade AG, Andrade LHSG. Epidemiologia do beber pesado e beber pesado episódico no Brasil: uma revisão sistemática da literatura. Rev Psiquistria Clínica 2008; 35(1):31-38.

28. Hinote BP, Cockerham WC, Abbott P. Psychological distress and dietary patterns in eight post-Soviet republics. Appetite 2009; 53(1):24-33.

29. Forsyth AK, Williams PG, Deane FP. Nutrition status of primary care patients with depression and anxiety. Aust J Prim Health 2012; 18(2):172-176.

30. Grunberg NE, Straub RO. The role of gender and taste class in the effects of stress on eating. Health Psychol 1992; 11(2):97-100. 
31. Zellner DA, Saito S, Gonzalez J. The effect of stress on men's food selection. Appetite 2007; 49(3):696-699.

32. Wardle J, Haase AM, Steptoe A, Nillapun M, Jonwutiwes K, Bellisle F. Gender differences in food choice: the contribution of health beliefs and dieting. Ann Behav Med 2004; 27(2):107-116.

33. Laitinen J, Ek E, Sovio U. Stress-related eating and drinking behavior and body mass index and predictors of this behavior. Prevent Med 2002; 34(1):29-39.

34. Torres S, Nowson C. Relationship between stress, eating behavior and obesity. Nutrition 2007; 23(1112):887-894.

35. Anton SD, Miller PM. Do negative emotions predict alcohol consumption, saturated fat intake, and physical activity in older adults? Behavior Modification 2005; 29(4):677-688

36. Cartwright M, Wardle J, Steggles N, Simon AE, Croker $\mathrm{H}$, Jarvis MJ. Stress and dietary practices in adolescents. Health Psychology 2003; 22(4):362-369.

37. Adam TC, Epel ES. Stress, eating and the reward system. Physiol Behav 2007; 91(4):449-458.

38. Foster MT, Warne JP, Ginsberg AB, Horneman HF, Pecoraro NC, Akana SF, Dallman MF. Palatable foods, stress, and energy stores sculpt corticotropin-releasing factor, adrenocorticotropin, and corticosterone concentrations after restraint. Endocrinology 2009; 150(5):2325-2333.

39. Laugero KD, Falcon LM, Tucker KL. Relationship between perceived stress and dietary and activity patterns in older adults participating in the Boston Puerto Rican Health Study. Appetite 2011; 56(1):194-204.

40. Tomiyama AJ, Schamarek I, Lustig RH, Kirschbaum C, Puterman E, Havel PJ, Epel ES. Leptin concentrations in response to acute stress predict subsequent intake of comfort foods. Physiol Behav 2012; 107(1):34-39.

41. Lazarus RS, Folkman S. Stress, appraisal and coping. New York: Springer Publishing Company, Inc; 1984.

42. Folkman S, Lazarus RS. If it changes it must be a process: study of emotion and coping during three stages of a college examination. J Pers Soc Psychol 1985; 48(1):150-170.

43. Polivy J, Herman CP. Mental health and eating behaviours: a bi-directional relation. Can J Public Health 2005; 96(Supl. 3):S43-6, S9-53.

44. Cobiac LJ, Vos T, Veerman JL. Cost-Effectiveness of Interventions to Promote Fruit and Vegetable Consumption. PLoS One 2010; 5:11.

Artigo apresentado em 05/10/2015

Aprovado em 10/05/2016

Versão final apresentada em 12/05/2016 
